\title{
Implementation of Artificial Neural Network Method for Estimating Connected Power and Electric Energy Consumption
}

\author{
Roub Nizaar $A^{1,2}$, Anik Nur Handayani ${ }^{1}$
}

Authors

${ }^{1}$ Department of Electrical Engineering Universitas Negeri Malang, Indonesia.

${ }^{2}$ Smart Power and Advanced Energy Systems Research Center, Batu, Indonesia.

Corresponding: roubnizaar@gmail.com
Abstract

Abstract-Electricity is vital for modern society's welfare Daily electricity usage depended on the customers' type. Hence. there was a difference between the connected power with consumption. Therefore, there needed an estimation method for long-term connected power and energy consumption to improve the safety of energy management and operation plan for the generator. This research used the Artificial Neural Network method with a backpropagation algorithm model to estimate the connected power and electricity consumption. This method has the advantage of following past patterns after the training process. This research used data such as total population, Gross Regional Domestic Product total customers, produced energy, remaining energy, distribution loss, total transformer, peak load, and load factor as the independen 1 data. The energy consumption and connected power served as the dependent data. The data was taken from Srengat Network Service Unit, East Java, for ten years, which started in 2008. This research used literature study, information and data collection, information and data process, data estimation and analysis, and conclusion as the procedures. Based on the results, the best network structure was 9-9. 2 with the $10^{-6}$ goal, 0.9 momentum value, and 0.15 learning rate tc produce the smallest Mean Squared Error of 0.00442 in 2015, Mean Absolute Percentage Error of $7.88 \%$ for the connected power, and $11.27 \%$ on electricity consumption target.

Keywords

transformer age, linear trend, load growth, ambient temperature

\section{Introduction}

Electricity is a vital factor in society's welfare. The welfare level is the main factor in daily electricity usage [1]-[5]. The utilization depends on the customers' type; hence, there was a difference in the connected power with electricity consumption. Electric supplier should consider the maximum consumption demand correctly until a defined period. The connected power to meet 2016 electricity consumption was $67 \mathrm{MW}$ while in 2017 was $72 \mathrm{MW}$. This occurrence shows that consumption increases every year. To fulfill the increasing demand, there needs a balance from the production and consumption to equalize the consumption with production level [6]. Therefore, there needs an estimation in long-term connected power and electricity consumption.

This estimation was performed to know the target level of connected power and electricity consumption accurately to improve the security of energy management, save the operational cost, and safety for production and consumption, and as a reference for the Operational Plan [7]-[11]. Based on the reference study, it can be concluded that the connected power and electricity consumption have complex factors and non-linear characteristics. A good estimation can be obtained using traditional methods. However, the Artificial Neural Network (ANN) with feed-forward and feed-backward functions and backpropagation algorithm is a high accuracy method with a small error level to find the non-linear connection, economic factor variations, and other factors, and adjusting itself on changes that occur [12]-[16].

\section{Network Architecture Formation}

The network architecture formation was modeled based on the obtained data. Figure 1 illustrates the network architecture, while Table I shows the network architecture structure. 
Fig. 1. Network Architecture

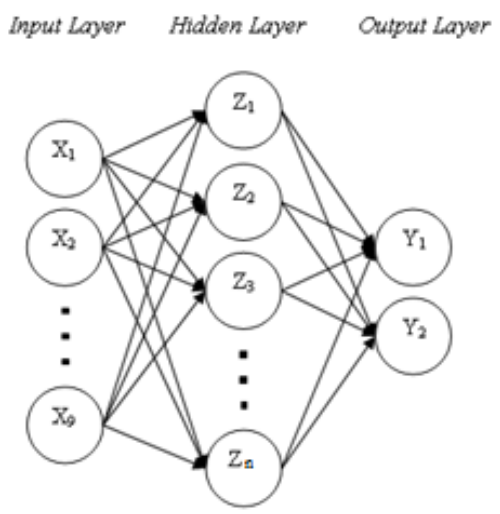

TABLE I

NETWORK ARCHITECTURE COMPOSITION

\begin{tabular}{|l|l|l|}
\hline \multicolumn{1}{|c|}{ Parameter } & \multicolumn{1}{c|}{ Amount } & \multicolumn{1}{c|}{ Description } \\
\hline Input Layer & 9 neurons & Research Data \\
\hline Hidden Layer & 9 neurons & Research Results \\
\hline Output Layer & 2 neurons & $\begin{array}{l}\text { Estimation of power and energy } \\
\text { consumption }\end{array}$ \\
\hline Epoch & 10,000 & Maximum epoch \\
\hline Training Function & Traingdx & - \\
\hline Activation Function & Binary Sigmoidal & - \\
\hline
\end{tabular}

After the error value in training was smaller than the targeted error, the final update load during training was used in the testing stage to observe whether the load and bias could be used and obtained a good result. Table II presents the input and target organization in this research.

TABLE II

INPUT AND TARGET PATTERNS

\begin{tabular}{|l|l|l|}
\hline \multicolumn{1}{|c|}{ Pattern } & \multicolumn{1}{|c|}{ Input Data } & \multicolumn{1}{c|}{ Target } \\
\hline 1 & $\begin{array}{l}\mathrm{X}_{1}-\mathrm{X}_{5} \text { were the independent } \\
\text { data from } 2008\end{array}$ & 2008 dependent data \\
\hline 2 & $\begin{array}{l}\mathrm{X}_{1}-\mathrm{X}_{5} \text { were the independent } \\
\text { data from } 2009\end{array}$ & 2009 dependent data \\
\hline$\cdot$ & $\cdot$ & $\cdot$ \\
\hline$\cdot$ & $\cdot$ & $\cdot$ \\
\hline 10 & $\begin{array}{l}\mathrm{X}_{1}-\mathrm{X}_{5} \text { were the independent } \\
\text { data from } 2017\end{array}$ & 2017 dependent data \\
\hline
\end{tabular}

3) Testing Evaluation

Optimizing the network architecture was conducted by trial and error in the targeted Mean Squared Error (MSE) during the training. The Mean Absolute Percentage Error (MAPE) was used o see the precision and accuracy of the estimation results on the real data [17]-[19]. Equation 1 shows the MAPE equation.

MAPE $=\frac{\sum \frac{|y i-f i|}{y i} x 100}{n}$

The $y i$ value is the real data, $f i$ is the estimation results, and $n$ is the total data. Table III presents the MAPE accuracy level in the estimation. 
TABLE III

MAPE ACCURACY LEVEL IN THE ESTIMATION

\begin{tabular}{|l|l|}
\hline \multicolumn{1}{|c|}{ MAPE Value } & \multicolumn{1}{c|}{ Accuracy Level } \\
\hline$\leq 10 \%$ & High \\
\hline $10 \%<x \leq 20 \%$ & Good \\
\hline $20 \%<x \leq 50 \%$ & Reasonable \\
\hline$>50 \%$ & Low \\
\hline
\end{tabular}

\section{Method}

\section{Research Framework}

This research is quantitative with secondary data analysis. Figure 1 displays a flowchart of the research framework.

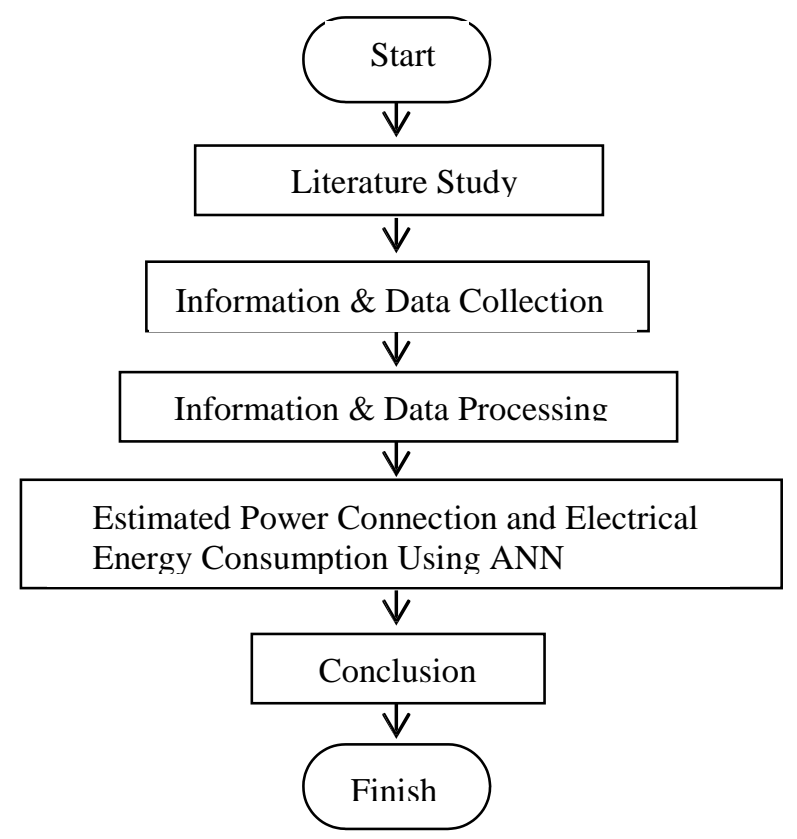

Fig. 2. Research Framework Chart

\section{B. Research Data}

The information and data in this research consisted of independent and dependent variables. Independent variables covered total population, Gross Regional Domestic Product in the regency, total customers, produced energy $(\mathrm{kWh})$, remaining energy $(\mathrm{kWh})$, distribution loss $\%$, total transformer, peak load, and load factor $(\%)$. Meanwhile, the dependent variables covered the consumed energy $(\mathrm{kWh})$ and connected power (VA) that also acted as the targeted data. The data was obtained from Srengat Network Service Unit, East Java and Blitar Regency Statistics. The data contained yearly data for the last ten years.

\section{Initial Data Processing}

The transformed data were processed using the ANN-backpropagation method in the initial data training to adjust the output range into (0.1) using the binary sigmoidal function. If the error were smaller than the targeted error, the training would stop. This study used the gradient descent with momentum backpropagation.

\section{Data Analysis}

Figure 2 presents the steps in estimating the connected power and electricity consumption. 


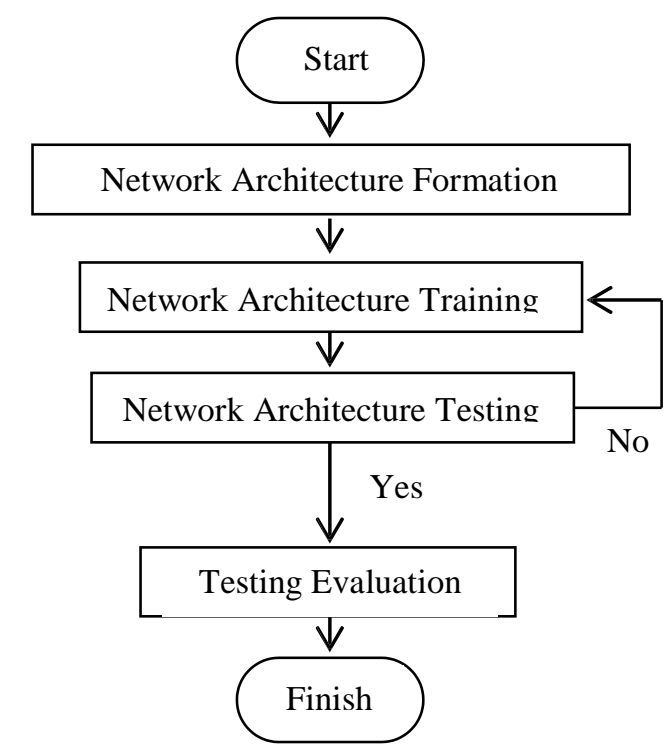

Fig. 3. Estimation Steps of Connected Power and Energy Consumption

\section{Result}

Based on the network architecture composition in Table I and the input and target patterns in Table II, this study obtained the best network architecture composition from the training and testing that was 9-9-2 with the goal of $10^{-6}$, momentum value of 0.9 , and 0.15 learning ratio. Below are the results of this research:

TABLE IV. COMPARISON OF ESTIMATION TRAINING

\begin{tabular}{|c|c|c|c|}
\hline Year & Target Value (VA) & JST Value (VA) & Error (\%) \\
\hline 2008 & $32,526,775$ & $32,615,611$ & 0.273 \\
\hline 2009 & $36,492,585$ & $36,296,363$ & 0.538 \\
\hline 2010 & $40,458,395$ & $40,667,869$ & 0.518 \\
\hline 2011 & $44,424,205$ & $44,245,877$ & 0.401 \\
\hline 2012 & $48,390,015$ & $48,478,252$ & 0.182 \\
\hline 2013 & $56,558,565$ & $56,552,204$ & 0.011 \\
\hline 2014 & $60,241,515$ & $60,236,464$ & 0.008 \\
\hline
\end{tabular}

TABLE IV. COMPARISON OF ENERGY CONSUMPTION DATA

\begin{tabular}{|c|c|c|c|}
\hline Year & Target Value(kWh) & JST Value (kWh) & Error (\%) \\
\hline 2008 & $45,137,523$ & $45,140,241$ & 0.006 \\
\hline 2009 & $50,547,295$ & $50,531,405$ & 0.031 \\
\hline 2010 & $55,957,068$ & $56,002,945$ & 0.082 \\
\hline 2011 & $61,366,841$ & $61,305,066$ & 0.101 \\
\hline 2012 & $66,776,613$ & $66,810,018$ & 0.050 \\
\hline 2013 & 76,358869 & $76,357,060$ & 0.002 \\
\hline 2014 & $83,905,547$ & $83,903,324$ & 0.003 \\
\hline
\end{tabular}


TABLE V. COMPARISON OF ESTIMATION TESTING RESULTS WITH THE ACTUAL CONNECTED POWER

\begin{tabular}{|l|l|l|l|}
\hline Year & \multicolumn{1}{|c|}{ Target Value (VA) } & \multicolumn{1}{|c|}{ JST Value (VA) } & \multicolumn{1}{|c|}{$(\boldsymbol{\%})$} \\
\hline 2015 & $64,047,015$ & $68,727,089$ & 7.31 \\
\hline 2016 & $67,821,615$ & $61,234,043$ & 9.71 \\
\hline 2017 & $72,597,565$ & $67,791,728$ & 6.62 \\
\hline \multicolumn{3}{|c|}{ MAPE } & 7.88 \\
\hline
\end{tabular}

TABLE VI. COMPARISON OF ESTIMATION RESULTS WITH THE ACTUAL ELECTRICAL ENERGY CONSUMPTION DATA

\begin{tabular}{|l|l|l|l|}
\hline Year & \multicolumn{1}{|c|}{ Target Value(kWh) } & \multicolumn{1}{|c|}{ JST Value (kWh) } & $\begin{array}{c}\text { Error } \\
(\%)\end{array}$ \\
\hline 2015 & $88,842,658$ & $84,414,009$ & 4.98 \\
\hline 2016 & $95,221,877$ & $97,342,762$ & 2.23 \\
\hline 2017 & $97,749,567$ & $123,743,804$ & 26.59 \\
\hline \multicolumn{3}{|c|}{ MAPE } & 11.27 \\
\hline
\end{tabular}

Based on the research results, the best result was in 2015 with 0.004422 MSE and 7.88\% MAPE for the connected power and $11.27 \%$ MAPE for the electricity consumption target. The network architecture composition recognized the patterns well and accurately delivered the estimation following the MAPE value. The estimated connected power had high accuracy, while the estimated electricity consumption had good accuracy. Higher accuracy in electricity consumption compared to the connected power was due to the various types of customers. Thus, consumption experienced large fluctuations. The changing patterns of the community's behavior followed the external factors (technology, climate, economy, others). Otherwise, the low accuracy in the connected power was due to the small demands of new installations each year. A small number of industries and low migration levels also influenced the electrical installation. Housing customers with middle-lower economical levels dominated the electricity installation in Srengat. Hence, the new installations only increased a little. The accuracy level on the consumption target each year could be improved by adding external factors and macroeconomic value as the input variables so that the network could adjust better.

\section{Conclusion}

Based on the research, the estimated connected power and electricity consumption in PT. PLN (Persero) UPJ Srengat, East Java, could be conducted using the Artificial Neural Network (ANN) method with feedforward and feed-backward functions from the backpropagation algorithm. The 0.9 momentum value and learning speed of 0.15 and network architecture of 9-9-2 was the best network. The smallest MSE proved a reasonable error adjustment in this research in 2015 that was 0.04422 and $7.88 \%$ MAPE value for the connected power, and $11.27 \%$ MAPE value for the electricity consumption target. The MSE was the indication that the network could adjust well or not. The value below one showed that the network could be used as the estimation method and adjust well. The external factors and macroeconomic value were correlated and influence the estimation and could be used as the input variables to improve the estimation accuracy.

\section{Acknowledgment}

I would like to acknowledge the Electrical Engineering Undergraduate Program, Electrical Engineering Department, Faculty of Engineering, the State University of Malang that gave the students a place to create. I also would like to express my gratitude to Smart Power and Advanced Energy Systems Research Center.

\section{References}

[1] F. Corcelli et al., "Sustainable urban electricity supply chain - Indicators of material recovery and energy savings from crystalline silicon photovoltaic panels end-of-life," Ecol. Indic., vol. 94, pp. 3751, Nov. 2018, doi: 10.1016/j.ecolind.2016.03.028.

[2] M. C. Carnero and A. Gómez, "Maintenance strategy selection in electric power distribution systems," Energy, vol. 129, pp. 255-272, Jun. 2017, doi: 10.1016/j.energy.2017.04.100.

[3] S.-Y. Huh, M. Jo, J. Shin, and S.-H. Yoo, "Impact of rebate program for energy-efficient household appliances on consumer purchasing decisions: The case of electric rice cookers in South Korea," Energy Policy, vol. 129, pp. 1394-1403, Jun. 2019, doi: 10.1016/j.enpol.2019.03.049. 
[4] Y. Sun, L. Zhu, Z. Xu, L. Xiao, J. Zhang, and J. Zhang, "Characteristic analysis and forecast of electricity supply and demand in APEC,” Glob. Energy Interconnect., vol. 2, no. 5, pp. 413-422, Oct. 2019, doi: 10.1016/j.gloei.2019.11.016.

[5] S. Hr. A. Kaboli, J. Selvaraj, and N. A. Rahim, "Long-term electric energy consumption forecasting via artificial cooperative search algorithm," Energy, vol. 115, pp. 857-871, Nov. 2016, doi: 10.1016/j.energy.2016.09.015.

[6] L. M. Korunović, A. S. Jović, and S. Z. Djokic, "Measurement-based evaluation of static load characteristics of demands in administrative buildings," Int. J. Electr. Power Energy Syst., vol. 118, p. 105782, Jun. 2020, doi: 10.1016/j.ijepes.2019.105782.

[7] L. T. Al-Bahrani, B. Horan, M. Seyedmahmoudian, and A. Stojcevski, "Dynamic economic emission dispatch with load demand management for the load demand of electric vehicles during crest shaving and valley filling in smart cities environment," Energy, p. 116946, Jan. 2020, doi: 10.1016/j.energy.2020.116946.

[8] V. M. Fthenakis, "End-of-life management and recycling of PV modules," Energy Policy, vol. 28, no. 14, pp. 1051-1058, Nov. 2000, doi: 10.1016/S0301-4215(00)00091-4.

[9] L. Geng, Z. Lu, L. He, J. Zhang, X. Li, and X. Guo, "Smart charging management system for electric vehicles in coupled transportation and power distribution systems," Energy, vol. 189, p. 116275, Dec. 2019, doi: 10.1016/j.energy.2019.116275.

[10] A. V. H. Sola and C. M. M. Mota, "Influencing factors on energy management in industries," J. Clean. Prod., vol. 248, p. 119263, Mar. 2020, doi: 10.1016/j.jclepro.2019.119263.

[11] S. Aznavi, P. Fajri, R. Sabzehgarm, and A. Asrari, "Optimal management of residential energy storage systems in presence of intermittencies," J. Build. Eng., p. 101149, Dec. 2019, doi: 10.1016/j.jobe.2019.101149.

[12] S. Mousavian, J. Valenzuela, and J. Wang, "Real-time data reassurance in electrical power systems based on artificial neural networks," Electr. Power Syst. Res., vol. 96, pp. 285-295, Mar. 2013, doi: 10.1016/j.epsr.2012.11.015.

[13] R. Hooshmand and M. Moazzami, "Optimal design of adaptive under frequency load shedding using artificial neural networks in isolated power system," Int. J. Electr. Power Energy Syst., vol. 42, no. 1, pp. 220-228, Nov. 2012, doi: 10.1016/j.ijepes.2012.04.021.

[14] S. M. Ashraf, A. Gupta, D. K. Choudhary, and S. Chakrabarti, "Voltage stability monitoring of power systems using reduced network and artificial neural network," Int. J. Electr. Power Energy Syst., vol. 87, pp. 43-51, May 2017, doi: 10.1016/j.ijepes.2016.11.008.

[15] M. Talaat, M. H. Gobran, and M. Wasfi, "A hybrid model of an artificial neural network with thermodynamic model for system diagnosis of electrical power plant gas turbine," Eng. Appl. Artif. Intell., vol. 68, pp. 222-235, Feb. 2018, doi: 10.1016/j.engappai.2017.10.014.

[16] J.-H. Menke, N. Bornhorst, and M. Braun, "Distribution system monitoring for smart power grids with distributed generation using artificial neural networks," Int. J. Electr. Power Energy Syst., vol. 113, pp. 472-480, Dec. 2019, doi: 10.1016/j.ijepes.2019.05.057.

[17] A. de Myttenaere, B. Golden, B. Le Grand, and F. Rossi, "Mean Absolute Percentage Error for regression models," Neurocomputing, vol. 192, pp. 38-48, Jun. 2016, doi: 10.1016/j.neucom.2015.12.114.

[18] S. Kim and H. Kim, "A new metric of absolute percentage error for intermittent demand forecasts," Int. J. Forecast., vol. 32, no. 3, pp. 669-679, Jul. 2016, doi: 10.1016/j.ijforecast.2015.12.003.

[19] L. Frías-Paredes, F. Mallor, M. Gastón-Romeo, and T. León, "Dynamic mean absolute error as new measure for assessing forecasting errors," Energy Convers. Manag., vol. 162, pp. 176-188, Apr. 2018, doi: 10.1016/j.enconman.2018.02.030. 